\title{
Contribuições do grupo de pesquisa F3P-EFICE para a formação de professores e Prática Pedagógica na ESEF/UFRGS e na Rede Municipal de Ensino de Porto Alegre
}

\author{
Andressa Pires Bopsin* \\ Lisandra Oliveira e Silva** \\ Vicente Molina Neto***
}

\begin{abstract}
Resumo: Neste artigo procuramos analisar de que forma o Grupo de Pesquisas Qualitativas F3P-EFICE, desde sua constituição, vem contribuindo para a formação de estudantes desta instituição e para a prática pedagógica dos professores da RMEPA. O processo analítico foi realizado sob a revisão bibliográfica dos estudos realizados pelo Grupo; e, através de documentos, foi resgatada a história deste. A partir das leituras realizadas, foi possível perceber que o Grupo inicia pautado na necessidade de aprofundar estudos que venham servir de subsídio à prática pedagógica e à formação de professores de Educação Física.
\end{abstract}

Palavras-chave: Grupo de Pesquisa; Formação de Professores; Educação Física.

\section{INTRODUÇÃO}

Este artigo faz parte de um projeto mais amplo intitulado: "ESCOLA DE EDUCAÇÃO FÍSICA DA UNIVERSIDADE FEDERAL DO RIO GRADE DO SUL (1940-2010): mapeando cenários da formação profissional e da produção do conhecimento em políticas públicas de esporte e lazer". Tal projeto é parte integrante

\footnotetext{
"Estudante de graduação em Licenciatura em Educação Física EsEF/UFRGS. Integrante do grupo de pesquisa F3P-EFICE/UFRGS. Bolsista da Rede Centro de Desenvolvimento do Esporte Recreativo e do Lazer (REDE CEDES) do Ministério do Esporte. Porto Alegre, RS, Brasil.

**Estudante do Curso de Doutorado do Programa de Pós-Graduação em Ciências do Movimento Humano (PPG-CMH) da EsEF/UFRGS. Integrante do grupo de pesquisa F3P-EFICE/UFRGS. Apoio: CAPES. Porto Alegre, RS, Brasil.

***Doutor em Ciências da Educação pela Universidade de Barcelona. Professor de graduação e pós-graduação na UFRGS. Apoio CNPq. Porto Alegre, RS, Brasil.
} 
do Núcleo UFRGS da Rede Centro de Desenvolvimento do Esporte Recreativo e do Lazer (REDE CEDES) do Ministério do Esporte. Este projeto, que está sendo desenvolvido em comemoração aos 70 anos da EsEF/UFRGS, é composto por três eixos. O primeiro eixo abarca o estudo historiográfico que propõe a reconstrução da memória desta instituição. Os outros dois eixos contemplarão as seguintes temáticas de pesquisa: a) Produção do conhecimento no âmbito das Políticas Públicas de esporte e lazer pela EsEF/UFRGS; b) Formação docente oferecida pela EsEF/UFRGS e sua repercussão na Rede Municipal de Ensino de Porto Alegre (RMEPA) e no sistema de ensino superior.

Para que todos os eixos pudessem ser estudados de forma aprofundada e qualitativa, optou-se por realizar uma pesquisa que, por sua vez, agrega quatro grupos de pesquisa da referida instituição de ensino: Grupo de Estudos sobre Cultura e Corpo (GRECCO), coordenado pela professora Silvana Vilodre Goellner e pelo professor Alex Branco Fraga; Grupo de Estudos Socioculturais em Educação Física (GESEF), coordenado pelo professor Marco Paulo Stigger; Núcleo de Estudos em História e Memória do Esporte e da Educação Física (NEHME) do Centro de Estudos Olímpicos, coordenado pela professora Janice Zarpellon Mazo; Grupo de Estudos Qualitativos Formação de Professores e Prática Pedagógica em Educação Física e Ciências do Esporte (F3P-EFICE), coordenado pelo professor Vicente Molina Neto.

Coube ao Grupo F3P-EFICE desenvolver o terceiro eixo, onde iremos analisar, identificar e compreender de que forma este coletivo, desde sua constituição, vem contribuindo com a prática pedagógica do professorado de Educação Física (EF) e de professores na RMEPA, no qual, desde o ano 2000, faz parte do cenário da formação profissional e da produção do conhecimento da EsEF/UFRGS.

Assim, a partir dos objetivos deste estudo sintetizamos o problema na seguinte questão: De que forma o grupo de pesquisa F3P-EFICE, desde sua constituição, contribui com a prática pedagógica do professorado e de futuros professores de EF da RMEPA? Iniciaremos este estudo com o resgate histórico do Grupo 
F3P-EFICE para que se possa compreender o seu surgimento no âmbito da produção de conhecimento. Em seguida, vamos argumentar sobre a Formação de Professores, a Prática Pedagógica e, por último, apresentaremos para encerrar o texto, as considerações finais.

\section{BREVE HISTÓRIA DO GRUPO F3P-EFICE}

Acreditamos que entender a perspectiva história e o contexto acadêmico que permite a emergência do Grupo F3P-EFICE é algo importante, uma vez que nos dá referências para alcançar os nossos objetivos: analisar, identificar e compreender de que forma este Grupo, desde sua constituição, vem tentando contribuir com a prática pedagógica do professorado e de futuros professores de EF da RMEPA.

No final da década de 90 a Secretaria Municipal de Educação (SMED) vinha executando sistematicamente vários programas de Formação Permanente em parceria com a UFRGS, sob a perspectiva de que "mudar é difícil, mas é possível e urgente" (FREIRE, 1991, p. 08). Já no ano de 1999, com o processo de intercâmbio entre EsEF/ UFRGS e a SMED já iniciado, um curso de formação permanente começou a ser planejado e executado especificamente no âmbito da EF por um grupo de professores desta Escola. O interesse dos professores ministrantes da atividade de Formação Permanente em aprofundar o conhecimento sobre os "Ciclos de Escolarização" implementada pela Administração Popular ${ }^{1}$ - convergia tanto com o interesse da SMED em ampliar e implementar a discussão sobre a especificidade da EF no Projeto Escola Cidadã ${ }^{2}$ quanto com a manifestação do interesse dos professores de EF das Escolas Municipais em fomentar a discussão desta disciplina no currículo escolar (MOLINA; MOLINA NETO, 2001).

\footnotetext{
${ }^{1}$ Gestão encabeçada pelo Partido dos Trabalhadores e que esteve à frente da Prefeitura de Porto Alegre entre 1989 e 2004.

${ }^{2}$ Ao dizer Escola Cidadã, estamos nos referindo à escola organizada por Ciclos de Formação, ou seja, uma nova forma de organização curricular que surge como proposta da SMED, do Município de Porto Alegre, no início da década de 90 do século passado, representando uma alternativa ao caráter excludente do contexto neoliberal que trata a Educação como mercadoria.
} 
O curso teve como título "a prática de investigar a própria prática", inspirado em Paulo Freire (1997). Isso porque, o foco da atividade era empreender uma análise sobre a Formação Permanente dos professores da Rede no contexto da Escola Cidadã, enfatizando a reflexão crítica sobre a prática pedagógica de EF nas escolas de Ensino Fundamental. O grupo de formadores - composto por 4 professores, sendo 3 da ESEF/UFRGS e 1 da UNISINOS - escolhido pela grande capacidade de escuta, assumiram o compromisso de ouvir os argumentos do professorado da Rede e, a partir daí, incentiválos a expor suas idéias e refletirem sobre seu trabalho, sua inserção nas escolas e sobre o papel da EF no currículo escolar. Para tanto, utilizaram as dinâmicas de produção e discussão coletiva num grande grupo de trabalho. As "falas" registradas desses grupos de trabalho foram sistematizadas pelos formadores e novamente discutidas no próprio grupo dos participantes para análise e convalidação interpretativa (MOLINA; MOLINA NETO, 2001). Findada estas etapas, os professores ministrantes produziram importantes reflexões sobre as representações que o professorado constrói no fazer docente e, a partir disso, sistematizaram suas interpretações e, segundo Molina e Molina Neto, uma delas foi a de que:

Os professores de educação física das Escolas da Rede Municipal de Ensino de Porto Alegre têm uma compreensão bastante clara da finalidade da atividade física na Escola Cidadã. A grande maioria converge, discursivamente, para o entendimento que a educação física trabalha com os elementos da cultura corporal do movimento humano e que este deve trabalhar com a intencionalidade pedagógica, capaz de socializar o estudante e torna-lo um cidadão crítico, criativo, participativo e autônomo e que, sobretudo, possa agir apropriando-se das pautas sociais de seu tempo histórico. (MOLINA; MOLINA NETO, 2001, p 81).

Além disso, foram percebidas dúvidas e incertezas por parte do professorado da RMEPA nesse espaço de formação. Uma das incertezas é quanto a especificidade dos conteúdos das aulas de EF, e algumas dúvidas são do "que" e "como" ensinar; como relacionar 
os conteúdos da EF com valores e atitudes; como trabalhar com a interdisciplinaridade, entre outros. Ainda, foi revelada a insatisfação com as teorias, pois estas não dão/davam respostas satisfatórias aos problemas enfrentados no cotidiano escolar, mostrando que a escola não está isolada do mundo e que é necessário ao professor fazer a mediação dos conhecimentos a serem trabalhados com a realidade em que estudantes, escola e comunidade estão inseridos.

Em decorrência destas reflexões e inquietações surgidas no curso de Formação Permanente, o grupo de estudos, - que desde o início dos anos 90 já se interessava e estudava a prática pedagógica do professorado de EF nas escolas públicas - composto por professores da EsEF/UFRGS e por professores da RMEPA, passou a se reunir sistematicamente a cada 20 dias, com a necessidade de aprofundar estudos que viessem a servir de subsídio para a prática dos professores de EF no espaço escolar, pois, como destaca Sanchotene (2007), as aulas de EF estão passando por algumas transformações importantes, sobretudo porque há a preocupação dos professores em procurar novos embasamentos que possibilitem o desenvolvimento da reflexão crítica da prática docente, que subsidie uma intervenção pedagógica crítica e compromissada socialmente.

No inicio do ano de $2001^{3}$, este grupo de estudos passou a ser denominado "Grupo de Estudos Qualitativos Formação de Professores e Prática Pedagógica em Educação Física e Ciências do Esporte" (F3P-EFICE) 4 , registrado no Diretório dos Grupos de Pesquisa do $\mathrm{CNPq}$ e a ter como local de referência as dependências da EsEF/UFRGS, onde suas reuniões sistemáticas são até os dias de hoje realizadas a cada 15 dias.

A escolha pelo método qualitativo de pesquisa partiu do entendimento de que este seria o mais adequado para analisar e

\footnotetext{
3É importante destacar que no final de 2000 o Programa de Pós-Graduação em Ciências do Movimento recebe a autorização da CAPES para operar em nível de doutorado e os documentos de avaliação da área de conhecimento educação física, na época, enfatizam a formação de grupos de pesquisa agregados aos Programas de Pós-Graduação existentes no Brasil como estratégia de desenvolvimento da produção de conhecimento.

${ }^{4}$ Atualmente, dentre os 16 Grupos de Pesquisa implantados no interior da EsEF/UFRGS, apenas o Grupo F3P-EFICE produz conhecimento sobre a prática pedagógica e a formação de professores na área da EF escolar.
} 
compreender o trabalho pedagógico no âmbito da EF escolar, dando vez e voz aos colaboradores com a racionalidade polidimensional. Além disso, a pesquisa qualitativa busca compreender um determinado contexto particular, partindo do pressuposto de que generalizações não são possíveis (NEGRINE, 2010), buscando em profundidade os significados que o próprio sujeito constrói em seu cotidiano docente.

Desde então, os estudos sobre Formação de Professores e Prática Pedagógica em Educação Física e Ciências do Esporte ganham materialidade em trabalhos de Iniciação Científica (IC), Dissertações de Mestrado, Teses de Doutorado, artigos científicos publicados em revistas e comunicações em anais de congressos nacionais e internacionais da área da Educação Física, Educação e afins.

É, então, com o coletivo de pesquisadores, constituído por estudantes de Mestrado, de Doutorado, de Pós-Doutorado, bolsistas de IC (estudantes de Graduação da EsEF/UFRGS) e com o auxílio de seus estudos que são compartilhadas vivências, tensões e dificuldades do fazer docente. Assim, através do exercício da reflexão crítica e permanente, tenta-se não somente compreender, mas superar os diversos problemas enfrentados no cotidiano do professorado, desde a Formação Inicial até a Formação Permanente, e de acordo com Wittizorecki (2001), em sua Dissertação de Mestrado, também apoiá-los em seus processos de reflexão e reconstrução das práticas educativas realizadas no âmbito das escolas.

Até o presente momento o Grupo já produziu 4 Teses de Doutorado, 16 Dissertações de Mestrado, 8 Trabalhos de Conclusão de Curso, 2 livros e diversas publicações em periódicos e comunicações em anais de congressos nacionais e internacionais. Presentemente estão sendo construídos 1 Projeto de Pós-Doutorado, 3 Projetos de Teses de Doutorado, 3 Projetos de Dissertações de Mestrado e 2 Projetos de IC.

É importante salientar que, apesar de o principal campo de investigação dos trabalhos do F3P-EFICE ainda serem as escolas 
da RMEPA ${ }^{5}$, o grupo já realizou diversos estudos em outros espaços, mantendo sempre a linha investigativa na prática pedagógica e/ou formação de professores. No total, são 20 produções - entre Teses, Dissertações, Trabalhos de Conclusão de Curso e os atuais Projetos - com estudos realizados "sobre" e "na" Rede e 15 estudos realizados em outros espaços que abrangem a prática pedagógica e a formação de professores na área da EF. Ver quadro a seguir:

\begin{tabular}{|c|c|c|}
\hline TÍTULO & \begin{tabular}{|c|} 
AUTOR (A), \\
ANO DE CONCLUSÃO, \\
FORMAÇÃO ACADÊMICA.
\end{tabular} & DESCRIÇÃO \\
\hline $\begin{array}{c}\text { Formação permanente de } \\
\text { professores de Educação } \\
\text { Física na RMEPA no } \\
\text { período de } 1989 \text { a } 1999 \text { : } \\
\text { um estudo a partir de } \\
\text { quatro escolas. }\end{array}$ & $\begin{array}{c}\text { GÜNTHER, M. C. C., } 2000 . \\
\text { Dissertação de Mestrado }\end{array}$ & $\begin{array}{c}\text { Estudo etnográfico que tenta compreen- } \\
\text { der os efeitos das atividades de formação } \\
\text { permanente na prática pedagógica dos } \\
\text { professores de Educação Física da } \\
\text { RMEPA. }\end{array}$ \\
\hline $\begin{array}{l}\text { O trabalho docente dos } \\
\text { professores de Educação } \\
\text { Física da RMEPA: um } \\
\text { estudo de quatro escolas } \\
\text { do Morro da Cruz. }\end{array}$ & $\begin{array}{l}\text { WITTIZORECK, E. S., } 2001 . \\
\text { Dissertação de Mestrado }\end{array}$ & $\begin{array}{l}\text { Estudo etnográfico que tenta } \\
\text { compreender o trabalho cotidiano dos } \\
\text { professores de Educação Física da } \\
\text { RMEPA que atuam em uma região da } \\
\text { cidade de Porto Alegre. }\end{array}$ \\
\hline $\begin{array}{l}\text { Planejamento de Ensino } \\
\text { dos professores de } \\
\text { Educação Física do } 2^{\circ} \text { e } 3^{\circ} \\
\text { ciclos da RMEPA: um } \\
\text { estudo do tipo etnográfico } \\
\text { em quatro escolas desta } \\
\text { rede de ensino. }\end{array}$ & $\begin{array}{c}\text { BOSSLE, F., } 2003 . \\
\text { Dissertação de Mestrado }\end{array}$ & $\begin{array}{l}\text { Estudo etnográfico que tenta } \\
\text { compreender o processo de planejamento } \\
\text { de ensino dos professores de Educação } \\
\text { Física da RMEPA e quais os elementos } \\
\text { constitutivos mais importantes. }\end{array}$ \\
\hline $\begin{array}{c}\text { A Síndrome do } \\
\text { Esgotamento Profissional: } \\
\text { o abandono da carreira } \\
\text { docente pelos professores } \\
\text { de Educação Física da } \\
\text { RMEPA. }\end{array}$ & $\begin{array}{c}\text { SANTINI, J., } 2004 . \\
\text { Dissertação de Mestrado }\end{array}$ & $\begin{array}{l}\text { Estudo descritivo exploratório que tenta } \\
\text { compreender o processo de abandono da } \\
\text { carreira docente dos professores de } \\
\text { Educação Física que atuam na RMEPA. }\end{array}$ \\
\hline $\begin{array}{l}\text { A interdisciplinaridade na } \\
\text { ação pedagógica do } \\
\text { professor de Educação } \\
\text { Física na RMEPA: um } \\
\text { estudo de caso. }\end{array}$ & $\begin{array}{l}\text { PEREIRA, R. R., } 2004 . \\
\text { Dissertação de Mestrado }\end{array}$ & $\begin{array}{l}\text { Estudo de caso etnográfico que tenta } \\
\text { compreender a interdisciplinaridade na } \\
\text { ação pedagógica dos professores de } \\
\text { Educação Física da RMEPA e que } \\
\text { elemento facilitam e dificultam as mesmas. }\end{array}$ \\
\hline $\begin{array}{l}\text { A avaliação nas aulas de } \\
\text { Educação Física na } \\
\text { RMEPA: um estudo } \\
\text { de caso }\end{array}$ & $\begin{array}{l}\text { OLIVEIRA, L. R, } 2005 . \\
\text { Iniciação Científica }\end{array}$ & $\begin{array}{l}\text { Estudo de caso que tenta compreender o } \\
\text { que é avaliado e como é feita a avaliação } \\
\text { nas aulas de Educação Física na } \\
\text { RMEPA. }\end{array}$ \\
\hline $\begin{array}{l}\text { A prática pedagógica dos } \\
\text { professores de Educação } \\
\text { Física e o currículo } \\
\text { organizado por ciclos - um } \\
\text { estudo etnográfico na } \\
\text { RMEPA. }\end{array}$ & $\begin{array}{l}\text { GÜNTHER, M. C. C., } 2006 . \\
\text { Tese de Doutorado }\end{array}$ & $\begin{array}{l}\text { Compreender a prática pedagógica dos } \\
\text { professores de Educação Física no } \\
\text { ensino fundamental da RMEPA a partir } \\
\text { da implantação do currículo organizado } \\
\text { por ciclos de formação e a construção do } \\
\text { conhecimento elaborado nessa } \\
\text { experiência }\end{array}$ \\
\hline
\end{tabular}

${ }^{5}$ Dentre as 96 escolas da RMEPA existentes, o F3P-EFICE já realizou estudos em 21 delas. 


\begin{tabular}{|c|c|c|}
\hline $\begin{array}{l}\text { Avaliação do processo de } \\
\text { ensino-aprendizagem nas } \\
\text { aulas de Educação Física nas } \\
\text { séries finais do ensino } \\
\text { fundamental. }\end{array}$ & $\begin{array}{l}\text { KULMANN, M. F. H., } 2007 . \\
\text { Iniciação Científica }\end{array}$ & $\begin{array}{c}\text { Compreender o processo de avaliação } \\
\text { nas aulas de Educação Física nas } \\
\text { séries finais do Ensino Fundamental } \\
\text { na RMEPA. }\end{array}$ \\
\hline $\begin{array}{l}\text { A atuação profissional e } \\
\text { política de uma professora } \\
\text { negra no contexto sócio- } \\
\text { educativo de uma escola da } \\
\text { RMEPA: um estudo de caso. }\end{array}$ & $\begin{array}{l}\text { ARAÚJO, M. L., } 2006 . \\
\text { Iniciação Científica }\end{array}$ & $\begin{array}{c}\text { Compreender a prática política- } \\
\text { pedagógica de uma professora negra } \\
\text { de EFI no processo de transformação } \\
\text { social do contexto sócio-educativo } \\
\text { onde ela atua. } \\
\end{array}$ \\
\hline $\begin{array}{l}\text { Um estudo de caso com } \\
\text { mulheres professoras sobre } \\
\text { o processo de identização } \\
\text { docente em Educação Física } \\
\text { na RMEPA. }\end{array}$ & $\begin{array}{c}\text { SILVA, L. O., } 2007 . \\
\text { Dissertação de Mestrado }\end{array}$ & $\begin{array}{c}\text { Compreender o processo de } \\
\text { identização da professoras de EFI da } \\
\text { RMEPA, identificando os elementos } \\
\text { constitutivos e as especificidades } \\
\text { que o constituem, na perspectiva } \\
\text { das professoras. }\end{array}$ \\
\hline $\begin{array}{l}\text { A relação entre as experiên } \\
\text { cias vividas pelos professores } \\
\text { de Educação Física e a sua } \\
\text { prática pedagógica: } \\
\text { um estudo de caso. } \\
\end{array}$ & $\begin{array}{l}\text { SANCHOTENE, M. U., } 2007 . \\
\text { Dissertação de Mestrado }\end{array}$ & $\begin{array}{l}\text { Identificar e compreender os } \\
\text { "habitus" docentes dos } \\
\text { professores de EFI da RMEPA. }\end{array}$ \\
\hline $\begin{array}{l}\text { O estudante negro na cultura } \\
\text { estudantil e na Educação } \\
\text { Física escolar. } \\
\end{array}$ & $\begin{array}{l}\text { SANTOS, M. V., } 2007 . \\
\text { Dissertação de Mestrado }\end{array}$ & $\begin{array}{c}\text { Compreender o significado que os } \\
\text { estudantes atribuem a negritude } \\
\text { nas escolas da RMEPA. }\end{array}$ \\
\hline $\begin{array}{c}\text { O impacto das mudanças } \\
\text { sociais na ação pedagógica } \\
\text { dos docentes de Educação } \\
\text { Física da RMEPA: } \\
\text { implantação e implementação } \\
\text { do projeto Escola Cidadã. }\end{array}$ & $\begin{array}{l}\text { DIEHL, V. R. O., } 2007 . \\
\text { Dissertação de Mestrado }\end{array}$ & $\begin{array}{c}\text { Identificar e compreender, na } \\
\text { perspectiva dos professores de EFI, } \\
\text { os efeitos das recentes } \\
\text { transformações históricos-sociais } \\
\text { na sua ação pedagógica no contexto } \\
\text { escolar organizado por ciclos } \\
\text { de formação. }\end{array}$ \\
\hline $\begin{array}{l}\text { As expectativas e os saberes } \\
\text { construídos pelos } \\
\text { professores de } \\
\text { Educação Física } \\
\text { na RMEPA. }\end{array}$ & $\begin{array}{l}\text { ROCHA, C. H., } 2006 . \\
\text { Iniciação Científica }\end{array}$ & $\begin{array}{l}\text { Compreender as expectativas e os } \\
\text { saberes que constroem os } \\
\text { professores de EFI na } \\
\text { relação de trabalho nas } \\
\text { escolas da RMEPA. }\end{array}$ \\
\hline $\begin{array}{l}\text { "O eu do nós": o professor } \\
\text { de Educação Física e a } \\
\text { construção do trabalho } \\
\text { coletivo na RMEPA. }\end{array}$ & $\begin{array}{l}\text { BOSSLE, F., } 2008 . \\
\text { Tese de Doutorado }\end{array}$ & $\begin{array}{l}\text { Compreender a contribuição dos } \\
\text { professores de EFI no processo de } \\
\text { construção do trabalho coletivo nas } \\
\text { escolas de ensino fundamental da } \\
\text { RMEPA. }\end{array}$ \\
\hline $\begin{array}{l}\text { Alternativas pedagógicas e } \\
\text { pessoais frente ao desgaste } \\
\text { no trabalho docente num } \\
\text { contexto de mudanças } \\
\text { sócio-culturais. }\end{array}$ & $\begin{array}{l}\text { LOURENÇO, B. L., } 2009 . \\
\text { Dissertação de Mestrado }\end{array}$ & $\begin{array}{l}\text { Identificar e compreender as } \\
\text { alternativas pedagógicas e pessoais } \\
\text { de professores de educação física da } \\
\text { RMEPA para evitar, superar e } \\
\text { amenizar o desgaste ocasionado } \\
\text { pelo trabalho docente. }\end{array}$ \\
\hline $\begin{array}{l}\text { Mudanças sociais e o traba- } \\
\text { lho docente do professorado } \\
\text { de Educação Física na escola } \\
\text { de Ensino Fundamental: um } \\
\text { estudo da RMEPA. }\end{array}$ & $\begin{array}{l}\text { WITTIZORECKI, E. S., } 2009 . \\
\text { Tese de Doutorado }\end{array}$ & $\begin{array}{l}\text { Compreender os efeitos das } \\
\text { transformações sociais na } \\
\text { organização do trabalho dos } \\
\text { professores de EFI nas escolas da } \\
\text { RMEPA, identificando os saberes e } \\
\text { estratégias que eles produzem para } \\
\text { enfrentar as demandas sociais, } \\
\text { culturais e educacionais da } \\
\text { comunidade escolar. }\end{array}$ \\
\hline
\end{tabular}

Quadro 1- Pesquisas realizadas na Rede Municipal de Ensino de Porto Alegre com professores de Educação Física (RMEPA). 


\begin{tabular}{|c|c|c|}
\hline $\begin{array}{l}\text { TITULO DO } \\
\text { PROJETO }\end{array}$ & $\begin{array}{l}\text { AUTOR (A), } \\
\text { FORMAÇÃO } \\
\text { ACADÊMICA. }\end{array}$ & DESCRIÇÃO \\
\hline $\begin{array}{l}\text { A violência escolar e sua } \\
\text { representação para os professores } \\
\text { de educação física das escolas } \\
\text { públicas de Porto Alegre. }\end{array}$ & $\begin{array}{l}\text { BOSSLE, F. } \\
\text { Projeto de Tese de } \\
\text { Pós-Doutorado }\end{array}$ & $\begin{array}{l}\text { Estudo de natureza qualitativa, } \\
\text { descritivo explicativo, que tenta } \\
\text { compreender a representação de } \\
\text { violência para os professores de } \\
\text { educação física de escolas públicas de } \\
\text { Porto Alegre frente às mudanças } \\
\text { sociais e seus desdobramentos no } \\
\text { cotidiano escolar. }\end{array}$ \\
\hline $\begin{array}{l}\text { As trajetórias de vida dos/as } \\
\text { estudantes-trabalhadores/as da } \\
\text { educação de jovens e adultos: o } \\
\text { significado da educação física }\end{array}$ & $\begin{array}{c}\text { REIS, J.A. P. } \\
\text { Projeto de Dissertação de } \\
\text { Mestrado }\end{array}$ & $\begin{array}{c}\text { Estudo de caso qualitativo que se } \\
\text { propõe a investigar o significado } \\
\text { da Educação Física nas trajetórias } \\
\text { de vida dos/as estudante } \\
\text { trabalhadores/as da EJA da RMEPA. }\end{array}$ \\
\hline $\begin{array}{l}\text { Os sentidos da escola na } \\
\text { atualidade: significados } \\
\text { conferidos pelo professorado } \\
\text { de Educação Física e por } \\
\text { estudantes do Ensino } \\
\text { Fundamental da RMEPA. }\end{array}$ & $\begin{array}{l}\text { SILVA, L. O. } \\
\text { Projeto de Tese de } \\
\text { Doutorado }\end{array}$ & \begin{tabular}{|} 
Compreender quais sentidos são \\
conferidos à escola e à Educação \\
Física pelo professorado dessa área \\
de conhecimento e por estudantes do \\
Ensino Fundamental da Rede \\
Municipal de Ensino de \\
Porto Alegre.
\end{tabular} \\
\hline
\end{tabular}

Quadro 2 - Projetos Em Andamento - Grupo de Pesquisa F3P-EFICE

\begin{tabular}{|c|c|c|}
\hline $\begin{array}{l}\text { O conhecimento pedagógico do } \\
\text { professor de Educação Física na } \\
\text { escola pública da Rede Estadual } \\
\text { de Ensino e sua relação com a } \\
\text { prática docente. }\end{array}$ & $\begin{array}{c}\text { SCHERER, A., } 2000 . \\
\text { Dissertação de Mestrado }\end{array}$ & $\begin{array}{l}\text { Estudo etnográfico que busca } \\
\text { identificar que conhecimentos } \\
\text { sustentam a prática pedagógica do } \\
\text { professor de educação física da escola } \\
\text { pública da rede estadual de ensino. }\end{array}$ \\
\hline $\begin{array}{l}\text { A prática docente de professores } \\
\text { de Educação Física do Ensino } \\
\text { Médio das escolas públicas de } \\
\text { Caxias do sul. }\end{array}$ & $\begin{array}{l}\text { FAGGION, C. A., } 2000 \\
\text { Dissertação de Mestrado }\end{array}$ & $\begin{array}{l}\text { Etnografia que tem como propósito } \\
\text { refletir acerca da construção da prática } \\
\text { docente de professores de Educação } \\
\text { Física do Ensino Médio das escolas } \\
\text { públicas de Caxias do sul. }\end{array}$ \\
\hline $\begin{array}{l}\text { A prática da Educação Física na } \\
\text { escola privada de Ensino Médio. }\end{array}$ & $\begin{array}{l}\text { BONONE, C. G. G., } 2000 . \\
\text { Dissertação de Mestrado }\end{array}$ & $\begin{array}{l}\text { A pesquisa é de corte qualitativo- } \\
\text { descritivo e predominantemente } \\
\text { etnográfica. O objetivo do trabalho foi } \\
\text { o de responder à seguinte questão: } \\
\text { Como o professor de Educação Física } \\
\text { constrói sua prática docente nas } \\
\text { escolas particulares de Ensino Médio } \\
\text { de Caxias do Sul? }\end{array}$ \\
\hline $\begin{array}{l}\text { Os conteúdos escolares da } \\
\text { Educação Física Fundamental. }\end{array}$ & $\begin{array}{l}\text { FREITAS, A. L. C., } 2001 \\
\text { Dissertação de Mestrado }\end{array}$ & $\begin{array}{l}\text { Estudo de perspectiva etnográfica que } \\
\text { busca identificar quais são os conhe- } \\
\text { cimentos desenvolvidos pelo compo- } \\
\text { nente curricular Educação Física em } \\
\text { uma escola pública de Gravataí. }\end{array}$ \\
\hline $\begin{array}{l}\text { O desafio da mudança na } \\
\text { Formação Inicial de professores: } \\
\text { o estágio curricular no curso de } \\
\text { licenciatura em Educação Física. }\end{array}$ & $\begin{array}{l}\text { SCHERER, A., } 2008 . \\
\text { Tese de Doutorado }\end{array}$ & $\begin{array}{l}\text { Aborda a formação de professores de } \\
\text { Educação Física com foco em uma } \\
\text { experiência de Estágio Curricular } \\
\text { Supervisionado desenvolvida em um } \\
\text { modelo participativo, buscando a } \\
\text { autonomia e espírito crítico dos } \\
\text { estagiários em relação a seu } \\
\text { compromisso social como professor } \\
\text { e cidadão. }\end{array}$ \\
\hline
\end{tabular}




\begin{tabular}{|c|c|c|}
\hline $\begin{array}{c}\text { A hegemonia do esporte } \\
\text { na escola. }\end{array}$ & $\begin{array}{c}\text { PERGHER, E. G., } 2008 . \\
\text { Iniciação Científica e TCC }\end{array}$ & $\begin{array}{l}\text { Estudo qualitativo baseado na } \\
\text { discussão crítica sobre o esporte } \\
\text { que analisa as implicações que esse } \\
\text { fenômeno social, no contexto } \\
\text { escolar, traz a partir da prática dos } \\
\text { professores de educação física. }\end{array}$ \\
\hline $\begin{array}{l}\text { A contribuição da formação } \\
\text { inicial de licenciatura em } \\
\text { Educação Física da EsEF/ } \\
\text { UFRGS para a prática } \\
\text { docente escolar. }\end{array}$ & $\begin{array}{l}\text { BERNARDI, G. B., } \\
2008 . \\
\text { Iniciação Científica } \\
\text { ETCC }\end{array}$ & $\begin{array}{l}\text { Aborda a formação profissional } \\
\text { para a docência escolar do curso } \\
\text { de licenciatura da EsEF/UFRGS, } \\
\text { com o objetivo de compreender } \\
\text { como o currículo da formação } \\
\text { inicial subsidia os estudantes de } \\
\text { educação física para a prática } \\
\text { docente em escolas públicas. }\end{array}$ \\
\hline $\begin{array}{c}\text { O espaço físico escolar a partir } \\
\text { do olhar dos professores de } \\
\text { Educação Física. }\end{array}$ & $\begin{array}{c}\text { OLIVEIRA, C. F., } 2008 . \\
\text { Iniciação Científica e TCC }\end{array}$ & $\begin{array}{l}\text { Estudo etnográfico que aborda a } \\
\text { relação do professor com o espaço } \\
\text { físico escolar e como, a partir de } \\
\text { suas próprias representações, estes } \\
\text { professores se apropriam deste } \\
\text { espaço nas aulas de } \\
\text { educação física. }\end{array}$ \\
\hline $\begin{array}{l}\text { Um estudo sobre a formação } \\
\text { política na Educação Física. }\end{array}$ & $\begin{array}{c}\text { SILVA, G. G., } 2009 . \\
\text { Dissertação de Mestrado }\end{array}$ & $\begin{array}{l}\text { Estudo apoiado no materialismo } \\
\text { histórico-dialético que analisa } \\
\text { como se articulam os elementos } \\
\text { que contribuem para a formação } \\
\text { política de professores de } \\
\text { educação física engajados em } \\
\text { diferentes instituições. }\end{array}$ \\
\hline $\begin{array}{l}\text { Formação Permanente e suas } \\
\text { relações com a prática do } \\
\text { professor de Educação Física } \\
\text { na Secretaria de Esportes, } \\
\text { Recreação e Lazer de } \\
\text { Porto Alegre. }\end{array}$ & $\begin{array}{l}\text { SCHAFF, I. A. B., } 2009 . \\
\text { Dissertação de Mestrado }\end{array}$ & $\begin{array}{l}\text { Estudo que busca os significados } \\
\text { que o professorado de educação } \\
\text { física da Secretaria Municipal de } \\
\text { Esportes, Recreação e Lazer de } \\
\text { Porto Alegre atribui ao seu } \\
\text { processo de formação permanente } \\
\text { e que impactos este processo } \\
\text { produz no cotidiano de sua } \\
\text { prática pedagógica. }\end{array}$ \\
\hline $\begin{array}{c}\text { O Cuso de Licenciatura em } \\
\text { Educação Física na UFRGS: } \\
\text { a voz discente }\end{array}$ & $\begin{array}{l}\text { DANIEL. J. V., } 2009 . \\
\text { Iniciação Científica } \\
\text { e TCC }\end{array}$ & $\begin{array}{l}\text { Estudo que visa compreender as } \\
\text { concepções de currículo dos/as } \\
\text { estudantes de Licenciatura em } \\
\text { Educação Física da UFRGS; } \\
\text { compreender quais eram as } \\
\text { expectativas iniciais destes/as } \\
\text { estudantes ao ingressarem na } \\
\text { Universidade; e, compreender } \\
\text { suas futuras perspectivas docentes. }\end{array}$ \\
\hline $\begin{array}{l}\text { A organização do trabalho } \\
\text { pedagógico na Formação } \\
\text { Inicial de professores de } \\
\text { Educação Física. }\end{array}$ & $\begin{array}{l}\text { FILIPPINI, I., } 2010 . \\
\text { Iniciação Científica } \\
\text { e TCC }\end{array}$ & $\begin{array}{l}\text { Estudo que tem por objetivos } \\
\text { compreender a organização do } \\
\text { trabalho pedagógico nos estágios } \\
\text { curriculares do curso de } \\
\text { Licenciatura em Educação Física } \\
\text { da ESEF/UFRGS e a formação de } \\
\text { professores nesse curso. }\end{array}$ \\
\hline
\end{tabular}

Quadro 3. Temas Transversais - Grupo de Pesquisa F3P-EFICE 


\begin{tabular}{|c|c|c|}
\hline $\begin{array}{c}\text { Concepções de escola } \\
\text { elaboradas por estudantes de } \\
\text { Educação Física. }\end{array}$ & $\begin{array}{l}\text { SILVEIRA, P. S., } 2011 . \\
\text { Projeto de Iniciação } \\
\text { Científica e TCC }\end{array}$ & $\begin{array}{l}\text { Estudo de cunho etnográfico que } \\
\text { busca entender quais as concepções } \\
\text { de escola que os estudantes de } \\
\text { educação física, da EsEF/UFRGS, } \\
\text { trazem de sua vida escolar e o } \\
\text { que muda após a faculdade. }\end{array}$ \\
\hline $\begin{array}{l}\text { A Organização do Trabalho } \\
\text { Pedagógico da EF na escola } \\
\text { Capitalista: um estudo da Rede } \\
\text { Municipal de Ensino de Nova } \\
\text { Santa Rita-RS. }\end{array}$ & $\begin{array}{l}\text { FRIZZO, G. F. E., } 2011 . \\
\text { Projeto de Tese de } \\
\text { Doutorado }\end{array}$ & $\begin{array}{l}\text { Este estudo tem por objetivo analisar } \\
\text { a organização do trabalho pedagógico } \\
\text { da EF e o trato com o conhecimento } \\
\text { desta disciplina, buscando explicitar } \\
\text { as contradições existentes na escola } \\
\text { capitalista relacionados a esta forma } \\
\text { de organização de sociedade } \\
\text { fundamentada no antagonismo } \\
\text { capital-trabalho. }\end{array}$ \\
\hline $\begin{array}{l}\text { Descoberta ou sobrevivência? } \\
\text { Caminhos percorridos pelos } \\
\text { professores de educação física } \\
\text { durante os primeiros anos de } \\
\text { atuação. }\end{array}$ & $\begin{array}{c}\text { CONCEIÇÃO, D. V. J. S., } \\
2011 . \\
\text { Projeto de Tese de } \\
\text { Doutorado }\end{array}$ & $\begin{array}{l}\text { Estudo que, através de narrativas, } \\
\text { propõe uma discussão sobre o } \\
\text { processo de construção da } \\
\text { identidade de professores novatos, a } \\
\text { partir do ciclo de desenvolvimento } \\
\text { docente, trabalho pedagógico e } \\
\text { história de vida. }\end{array}$ \\
\hline $\begin{array}{l}\text { A formação dos educadores } \\
\text { sociais de esporte e lazer no } \\
\text { programa esporte e lazer da } \\
\text { cidade de Porto Alegre/RS. }\end{array}$ & $\begin{array}{l}\text { TONDIN, G. } 2011 . \\
\text { Projeto de Tese de } \\
\text { Mestrado }\end{array}$ & $\begin{array}{l}\text { Trata de uma pesquisa que analisa a } \\
\text { formação profissional do educador } \\
\text { social, no Programa Esporte e Lazer } \\
\text { da Cidade, implementado pelo } \\
\text { Ministério do Esporte, em Porto } \\
\text { Alegre. Objetiva compreender como } \\
\text { os conceitos socializados nas } \\
\text { formações, impactam a prática } \\
\text { pedagógica do educador. }\end{array}$ \\
\hline
\end{tabular}

Quadro 4 - Projetos Temas Tranversais - Grupo de Pesquisa F3P-EFICE

O coletivo, do mesmo modo, entende que a pesquisa não é o único instrumento para produção do conhecimento, mas um importante elemento para essa constituição. Portanto, o seu compromisso em produzir conhecimento não fica apenas no campo das teorias. Buscam-se formas de socializar a produção do conhecimento e permitir um acúmulo significativo para a área da $\mathrm{EF}$, principalmente no que diz respeito às temáticas: pesquisa qualitativa, práticas pedagógicas e formação de professores. Pois, fazemos pesquisa por acreditar na educação e que esta possa vir a contribuir em possíveis mudanças nas políticas sociais.

Tendo em vista esta concepção, o grupo já realizou três Seminários de Pesquisa Qualitativa, buscando superar a carência de eventos que tratem destas temáticas. $\mathrm{O}$ último seminário foi realizado no ano de 2010, cuja temática abordada foi especificamente a Pesquisa e a Formação de Professores. Diferentemente dos outros dois Seminários, o Grupo procurou também dar uma especial atenção 
a pesquisadores da área da Dança e da Fisioterapia ${ }^{6}$ devido à necessidade de avanço científico nestas áreas em relação à pesquisa qualitativa.

Como pudemos observar a emergência e a consolidação do F3P-EFICE se faz articulando duas ações fundamentais. De um lado uma política de pós-graduação que incentivou os professores, pesquisadores e estudantes a se organizarem coletivamente para produzir conhecimento científico na área de conhecimento e por outro lado o interesse de trabalhadores da educação física comprometidos com a qualificação e a formação dos professores de educação física e o trabalho docente desse coletivo docente que se realiza cotidianamente nas escolas públicas de ensino fundamental.

\section{GRUPO F3P-EFICE E A FORMAÇÃO DE PROFESSORES}

Nessa seção vamos aprofundar a discussão sobre temas que têm despertado a principal linha de pesquisa do F3P-EFICE nestes 11 anos de existência: a formação de professores (Inicial e Permanente) e a prática pedagógica na área da $\mathrm{EF}$

Analisaremos a formação docente oferecida pela EsEF/UFRGS e sua repercussão na RMEPA e no ensino superior dessa especificidade disciplinar. Também identificaremos e compreenderemos de que forma este coletivo, desde sua constituição, vem contribuindo com a prática pedagógica do professorado de EF e de futuros professores na RMEPA, tanto na Formação Inicial como na Permanente.

A EsEF/UFRGS, no ano de 2010, completou 70 anos de existência. Foi a primeira Instituição de Ensino Superior formadora de professores de EF implantada no Estado do Rio Grande do Sul. Também, é considerada uma das primeiras escolas de EF fundada no país para atender a formação de professores civis (DACOSTA, 1971).

\footnotetext{
${ }^{6}$ No ano de 2009, foram implantados dois novos cursos nas dependências da EsEF/UFRGS: Dança e Fisioterapia.
} 
Embora esse fato faça com que a Escola tenha um papel importante no cenário da Formação de Professores de EF entre as Instituições de Ensino Superior (IES), há estudos no interior do próprio Grupo - como os de Bernardi (2008) e Oliveira et al. (2010) - que apontam lacunas que ficam na Formação de Professores da EsEF/ UFRGS. É interessante salientar que estes autores foram bolsistas de IC no F3P-EFICE. O que nos remete a pensar que suas escolhas por investigações que tratem da Formação Inicial e de suas limitações, emergem de suas visões críticas quando vivenciam as dificuldades da prática docente durante a graduação. Estas lacunas também são apontadas nas investigações do grupo realizadas na Rede e, as quais, é possível ver a seguir.

\subsection{O CURRÍCULO NA FORMAÇÃO DE PROFESSORES}

Durante a revisão dos estudos do Grupo sobre a Formação Inicial, foi possível perceber que o currículo de formação de professores de educação física apresenta debilidades. Um fator que evidencia a debilidade na formação de professores na escola, e que apareceu num dos estudos, é o distanciamento entre os cursos de formação de professores de $\mathrm{EF}$ e o âmbito da escola. Este, por sua vez, decorre da própria constituição do currículo desta Instituição e em grande parte das IES (OLIVEIRA et al., 2010).

Outro fator observado no currículo e os quais também aparecem nas investigações do F3P-EFICE, é o fato de que a "teoria estudada na graduação esquece as práticas educativas dos professores de $\mathrm{EF}$, e elege como principal o estudo da estruturação do esquema corporal, do movimento humano e da saúde". (OLIVEIRA et al., 2010, p. 125)

Estes fatores nos levam a crer que, além do distanciamento entre os cursos formadores do professorado de EF, também há um grande desinteresse por parte de futuros professores ou de professores já graduados em atuarem em escolas públicas. O desinteresse dos estudantes, ainda na Formação Inicial, é devido à "perda de importância da formação pedagógica em detrimento de 
uma formação mais técnica, juntamente à crescente desvalorização do magistério" (GUNTHER; MOLINA NETO, 2000, p. 73).

\subsection{TEORIA E PRÁTICA NO CURRÍCULO}

Ainda sobre o currículo, uma questão significativa que envolve a Formação de Professores e que, portanto, limita a Formação Inicial em Educação Física com o trato do mundo escolar, é o fato de a teoria, com frequiência, está desvinculada com o dia-dia das aulas. Esta desvinculação apareceu no trabalho de Bernardi (2008) como bolsista de IC. Nesse trabalho intitulado "A Contribuição da Formação Inicial de Licenciatura em Educação Física da EsEF/UFRGS para a Prática Docente Escolar", esse autor sublinha que durante o período de Graduação os estudantes passam imersos em teorias e ao chegar nos últimos semestres do curso de Licenciatura se deparam com a realidade existente fora dos muros da Academia, tentando lidar com os estudantes reais e com a complexidade social estrutural impactante das escolas. Sobre isso, uma das colaboradoras de Bernardi, diz que:

[...] escola aqui no livro é legal, é muito legal, que é tudo fácil, tu propõe coisas que eles vão fazer, aqui na esef quando a gente faz um exercício de recreação todo mundo faz, todo mundo sabe como fazer o movimento, todo mundo fica ali até o final, sabe, ninguém sai correndo ou bate no coleguinha, não, não é assim, aqui na esef tudo funciona, aqui é o mundo das maravilhas, pensa bem. E tu chega lá na escola, nada disso! Tu propõe oito atividades e tu faz uma, porque a turma não te escutou do jeito que..eles não fizeram silêncio do jeito que aqui na esef tu faz, entendeu? Então como é que tu vai preparar uma pessoa que vai trabalhar com pessoas, com outro público? Que é um público de acadêmicos, aqui, que é muito fácil de trabalhar. (BERNARDI, 2008, p. 50)

Como dito anteriormente, a prática docente escolar pode ser vivenciada apenas nos últimos semestres do Curso. Fato esse que apareceu como mais um dentre os problemas no que tange o ensino 
e aprendizagem nos processos pedagógicos das aulas de EF, "desvirtuando e prejudicando a construção de saberes dos estudantes de graduação" (BERNARDI, 2008, p. 54), ainda sinaliza para o fato de que:

[...] por mais que tenham conhecimentos específicos para a prática, fica uma lacuna no que diz respeito ao desenvolvimento de uma capacidade reflexiva dos graduandos sobre sua própria prática. $\mathrm{O}$ conhecimento específico e técnico é muito bem trabalhado no processo de formação, mas os processos reflexivos são negados, já que o currículo se constitui numa estrutura terminalista, com os estágios ao fim do curso, impossibilitando uma reflexão posterior em outros espaços do processo de formação. (BERNARDI, 2008, p. 54).

Apesar destes depoimentos e achados emergirem de estudantes, - seja de colaboradores, seja de bolsistas de IC - estas afirmações sobre a Formação Inicial de professores de EF aparecem em estudos onde professores em exercício reforçam o entendimento de que o contato com a realidade das escolas públicas se dê desde o início da Graduação, pois:

Trabalhando com classes populares, tudo que aprendeu dentro da faculdade aqui tu não..., a única coisa que tu usa assim, vamos dizer, claro, e desporto, o futebol se joga com o pé e tem regras dele, claro; mas, às vezes, até tu tem que modificar um pouco dessas regras, para poder adequar ao nosso aluno. Então assim tu tem que adequar aquilo que tu aprendeu a tua realidade. Porque a tua realidade é não ter quadra, é não ter bola boa, é tu não ter lugar coberto, é tu ter que dar uma aula de Educação Física dentro de uma sala de aula com cadeira e com mesa, porque tem que ficar ali. Então assim, é adequar aquilo que tu aprendeu na faculdade para lidar com esse pessoal, que é muito difícil, é muito difícil. (professora de Educação Física do II e III Ciclos, 25 anos de experiência docente) (WITTIZORECKI; MOLINA NETO, 2005, p. 60) 
A partir de alguns estudos realizados, pode-se então ponderar que a necessidade de uma formação mais próxima da realidade escolar é um anseio tanto do estudante de graduação, quanto de professores que já estão inseridos no contexto da escola.

\subsection{ENSINO, PESQUISA E EXTENSÃO NA FORMAÇÃO INICIAL}

O Grupo F3P-EFICE compartilha o pressuposto de que um dos compromissos da Universidade Pública é garantir, além do acesso ao ensino, o contato com a pesquisa e a extensão. Porém, os autores colocam que o que se percebe é um déficit no currículo da EsEF/UFRGS em relação a esta tríade:

A Formação Inicial de professores de EF na UFRGS, no entanto, não vem conseguindo dar conta da pesquisa científica ao longo da formação do estudante de graduação, uma vez que esse processo, no que tange ao currículo do curso em questão, está restrito a uma disciplina de Metodologia da Pesquisa em EF e aos Trabalhos de Conclusão de Curso I e II, que preveem a produção de um estudo científico pelo aluno de graduação durante os dois últimos semestres do curso. (OLIVEIRA et al., 2010, p. 126)

Como se pode observar o contato com a produção do conhecimento se dá através dos grupos de pesquisa, porém, não são todos os estudantes que conseguem a inserção nestes núcleos e, por vezes, terminam o curso sem o contato suficiente com a produção do conhecimento necessário para a aprendizagem do processo pedagógico. Nesse sentido, os autores acima citados enfatizam a extrema importância de suas participações no Grupo F3P-EFICE e o que isto contribui na formação do estudante de graduação:

A experiência científica permite, através das reuniões e discussões, da aproximação com as produções já realizadas pelos integrantes do coletivo, além do próprio contato do estudante com o lócus a ser investigado, que os graduandos conheçam a realidade 
escolar, não de forma idealizada, mas como ela realmente é, ou seja, com as possibilidades e limitações do trabalho pedagógico (OLIVEIRA et al., 2010, p. 125).

\subsection{Fragmentação do Curso de EF em bacharelado E LICENCIATURA}

Mencionamos em outro lugar deste texto sobre o distanciamento que há entre os cursos de EF e o âmbito escolar. Além disso, foi visto que o principal foco dos estudos no currículo da Graduação são: o esquema corporal, o movimento humano e a saúde. Esta estruturação, além de distanciar a formação de professores de EF da área escolar, foi ainda mais acentuada com a fragmentação do Curso de EF em Bacharelado e Licenciatura, resultado de uma disputa pela identidade da grande área saúde, geralmente vista numa perspectiva mais biomédica, e da grande área educação, vista numa perspectiva mais sócio-cultural. Sobre isso, os autores ainda colocam que:

De um lado estão aqueles que buscam agregar os
conhecimentos produzidos pela educação física à
medicina, na busca de maior legitimidade científica,
muitas vezes tentando retirar o caráter educativo
da área. De outro, estão aqueles que entendem que
não existe Educação Física sem um fundamento
pedagógico. Para estes últimos, a formação docente
é um dos elementos mais marcantes da identidade
profissional da área. (NUNES; FRAGA, 2006, p.
300-301).

Contudo, atualmente a EsEF/UFRGS vem passando por uma ampla reestruturação curricular, onde a comunidade esefiana discute fortemente a possível unificação dos cursos (Bacharelado e Licenciatura), buscando uma formação unificada de qualidade para os professores de EF. Estas discussões vieram do entendimento de que o atual currículo não subsidia a formação humana e acadêmica dos futuros professores de EF e, da mesma forma, precariza ainda mais as suas atuações em decorrência da fragmentação do 
conhecimento e da forma como o currículo está posto para os estudantes da Graduação de EF, ou seja, de forma etapista e terminalista.

\subsection{FORMAÇÃO PERMANENTE}

Entendemos por Formação Permanente "os projetos de formação pessoal e profissional nos quais o professor participa, antes, durante e depois da Formação Inicial, por decisão própria ou atendendo orientações das diferentes instâncias da administração a qual está vinculado" (MOLINA; MOLINA NETO, 2001, p. 74).

No ponto onde realizamos um breve resgate histórico do Grupo, foi possível compreendermos como e quando o F3P-EFICE passou a ganhar materialidade. Foi através de um curso de Formação Permanente que um grupo de professores passou a perceber, com sensibilidade e capacidade de escuta, as angústias e incertezas que compõem a luta diária de ser professor no exercício desta profissão.

Com isso, este coletivo passou a focar seus estudos com o sentido de poder contribuir na Formação Permanente do professorado da RMEPA. Sobre isso, Gunther (2000), em sua Dissertação de Mestrado, sugere que os seus achados a levaram compreender que as diferentes experiências profissionais, o fazer pedagógico diário, suas possibilidades e limites de autonomia docente e a crescente proletarização do magistério são aspectos que vão para muito além de sua formação inicial e cursos de aperfeiçoamento e que estes aspectos permeiam, então, o processo formativo, influenciando na sua ação docente. Ainda, Günther e Molina Neto (2000, p. 73, grifo do autor) entendem que o "processo formativo de professores é um continuum, que se inicia antes mesmo do seu ingresso na graduação e se estende por toda a sua vida profissional."

Dentre as várias produções deste Grupo são diversos os temas abordados que trazem elementos sobre a reflexão da prática docente. Pois, exercer tal profissão foi, e ainda é, um desafio nos parâmetros que a Educação se encontra: volume de trabalho, baixos salários, descaso por parte dos governantes com a educação pública e 
problemas de ordem social (drogadição, evasão escolar, violência, entre outros), são algumas das dificuldades que o professor encontra no seu cotidiano de trabalho. Desta forma, Molina Neto, Bossle e Wittizorecki argumentam que não apenas o modo de Formação Inicial está esgotado,

[...] mas as políticas de formação permanente e os princípios orientadores também o estão, pois se assentam muito mais em marcos legais e interesses corporativos do que sobre a vida nas escolas. Os cursos de formação permanente podem até se constituir em uma opção de ilustração ou lazer e recreação para os docentes, mas, do ponto de vista da qualificação da prática pedagógica nas escolas e da capacidade docente para resolver problemas semelhantes aos relatados acima, somos céticos, pois nos parece algo que se aproxima da insensatez, do desperdício de dinheiro público e da demagogia política (MOLINA NETO; BOSSLE; WITTIZORECKI, 2010, p. 142-143).

Frente a estes problemas é possível considerar que, assim como a Formação Inicial, a Formação Permanente deve ser constituída de elementos significativos para o professorado. Por isso, o foco dos estudos do F3P-EFICE é em torno da prática pedagógica e da formação de professores, para que estes venham a servir como auxílio, antes, durante e após sua Formação Inicial e, assim, auxiliando na Formação Permanente do sujeito pesquisador/colaborador.

\section{Grupo F3P-EFICE E A PRÁtICA PEDAGÓGICA}

Nos trabalhos realizados pelos pesquisadores do Grupo emergem diversos problemas e incertezas vivenciados por estes e por colegas de profissão em seus cotidianos do trabalho docente. Estas decorrem dos problemas inerentes dos atuais parâmetros de educação que o Brasil vivencia, descritos no ponto anterior.

Com essas decorrências, o "sofrimento" e o "desencanto" por parte do professorado levam a um "descomprometimento pessoal" com o trabalho docente (SANTINI, 2009). Nesse sentido, o autor diz que: 
[...] poder-se-ia pensar que essas reações emocionais e corporais estivessem relacionadas, entre outras, à falta de estímulo das instituições com os professores para desenvolver um ensino de qualidade; aos currículos inadequados para a formação dos jovens; à decepção de docentes com o ensino público e às deficientes condições de trabalho do professor. Esses fatores apontam para um desgaste profissional que leva muitos professores, com o passar do tempo, a experimentarem a Síndrome do Esgotamento Profissional (SEP) e, como consequência, ao abandono do próprio trabalho, optando por uma nova profissão" (SANTINI, 2009, p. 122).

Na Rede, com a implantação do sistema por ciclos, proposto pela Escola Cidadã, o fazer docente se tornou ainda mais desafiador. São desafios que compreendem desde a questão da interdisciplinaridade no trabalho docente coletivo, passando pelo entendimento do significado da EF no contexto da Escola Cidadã. Nesse sentido, Bossle (2008), em sua Tese de Doutorado, trata do trabalho docente coletivo, pois em sua Dissertação de Mestrado, concluída no ano de 2003, identificou que os professores de EF construíam suas práticas educativas de maneira isolada e que não percebiam o trabalho coletivo proposto no projeto pedagógico como algo possível de ser realizado.

As dificuldades em realizar o ensino interdisciplinar, que o Projeto Político Pedagógico da RMEPA prevê como eixo norteador, decorre desde a formação profissional passando pela estrutura física e curricular da escola, que demonstra não terem se alterado de forma significativa para possibilitar ações interdisciplinares. Ainda, é importante salientar o fato de que, majoritariamente, o professorado não passou pela vivência do ensino por ciclos durante sua formação - tanto no Ensino Fundamental como no Ensino Superior - e, sim, pela formação seriada e etapista.

Neste sentido, Wittizorecki e Molina Neto (2005, p. 47) dão destaque em seus estudos a investigação de "como os professores desta rede construíam seu trabalho decente e como articulavam suas 
ações frente às singularidades do projeto-administrativo-pedagógico da mesma." Ao tratar do trabalho docente, Wittizorecki e Molina Neto (2005) dizem que seus estudos foram feitos:

[...] a partir da perspectiva de professores, preocupados e comprometidos com os conflitos e dificuldades presentes no cotidiano das escolas, entendendo que estes conflitos e dificuldades surgem na medida em que as finalidades educativas propostas pela administração municipal ou as intervenções pedagógicas que se realizam não são suficientemente compreendidas pela comunidade educativa (WITTIZORECKI; MOLINA NETO, 2005, p. 48).

A opção em realizar a pesquisa a partir da perspectiva dos professores se deu através do entendimento de que tanto o pesquisador como o colaborador contribui para a construção do aprendizado no processo de pesquisa e que essa relação se dá "entre sujeitos" e não "sobre sujeitos" (SILVA, 2009 b, p. 143).

Sobre essa forma de fazer pesquisa, Gunther e Sanchotene (2010) escrevem sobre o que chamam de "Processo de Devolução". Onde, antes mesmo da publicação da pesquisa, os achados são discutidos e compartilhados com os professores/colaboradores. É importante salientar que as autoras - Gunther (2006) e Sanchotene (2007) - ao concluírem suas pesquisas, promoveram um encontro com os professores/colaboradores com o intuito de discutirem sobre os achados e, inclusive, estes puderam sugerir algumas mudanças no trabalho, como por exemplo, o título.

Durante o "processo de devolução" um dos colaboradores da pesquisa sinalizou sobre a importância da presença da pesquisadora para a reflexão "sobre o que estavam fazendo nas aulas, o porquê de fazerem de tal forma e de onde provinha esta ação" (GUNTHER; SANCHOTENE, 2010, p. 45). Ainda, as autoras apresentam o depoimento de um professor/colaborador que retrata o que foi dito anteriormente: 
[A tua presença] despertou um pouco essa discussão sobre a prática: de que forma a gente está fazendo, o que a gente está fazendo, a partir de onde, porque a gente faz. A gente passa a pensar de outro jeito. Em como a gente faz e de onde tira isso, porque a gente continua fazendo... (GUNTHER; SANCHOTENE, 2010, p. 45)

Concluímos que esta forma de investigação tenta superar, ou ao menos diminuir, tanto a relação de poder que existe entre pesquisador/pesquisado quanto com o "distanciamento e a desigualdade de poder entre a Universidade e a escola" (GUNTHER; SANCHOTENE, 2010, p. 38).

\section{Considerações Finals}

Como pôde ser observado, utilizamos em nossas citações um amplo material produzido pelos professores/pesquisadores que constituíram o Grupo em tempo recente ou o constituem. Os trabalhos realizados pelo F3P-EFICE agrupam estudos riquíssimos que, colaboraram com o principal objetivo deste texto: analisar, identificar e compreender de que forma este coletivo, desde sua constituição, vem contribuindo com a prática pedagógico do professorado de EF e de futuros professores na RMEPA, no qual, desde o ano 2000, faz parte do cenário da formação profissional e da produção do conhecimento da EsEF/UFRGS.

Para tanto, se por um lado a escolha por este referencial colaborou para a produção deste texto, por outro, escolher algumas citações, que fazem parte das investigações do Grupo, não foi tarefa fácil. Pois, são muitas que contribuíram, contribuem e continuarão contribuindo com a prática e a formação dos trabalhadores da EF. De outra parte, esperamos que as referências utilizadas possam instigar a comunidade acadêmica no sentido de buscar os estudos deste Grupo e que esses possam os auxiliar no trabalho diário como professor e/ou pesquisador reflexivo e crítico.

Quanto às análises e identificações sobre as contribuições que o Grupo vem desenvolvendo no âmbito da produção do conhecimento, 
foi possível compreender, a partir das leituras realizadas durante a revisão bibliográfica, que este coletivo, desde o seu surgimento, trabalha com o principal objetivo de compreender e superar problemas encontrados no cotidiano do professor em seu local de trabalho: a escola. É com seus estudos que se procura aprofundar as discussões que possam vir a servir como subsídio no espaço escolar. Essa perspectiva vem através da reflexão "da" e "sobre" a prática, ou seja, no processo permanente de reflexão: "a prática de investigar a própria prática".

Porém, observou-se que existem outros fatores que levam o coletivo a pesquisar e se reunir sistematicamente, que não somente os aspectos que permeiam as escolas da RMEPA, mas, também, aspectos que permeiam a formação de professores e a prática pedagógica em outros âmbitos. Essas pesquisas, que denominamos como "temas transversais", procuram aprofundar temas, como: a prática da EF na escola privada de Ensino Médio (BONONE, 2000); os conteúdos escolares da EF Fundamental (FREITAS, 2001); a hegemonia do esporte na escola (PERGHER, 2008); o espaço físico escolar a partir do olhar dos professores de EF (OLIVEIRA, 2008); a contribuição inicial de licenciatura em EF da EsEF/UFRGS para a prática docente escolar (BERNARDI, 2008); Formação Política na EF (SILVA, 2009 a); organização do trabalho pedagógico na Formação Inicial de professores de EF (FILIPPINI, 2010); escola itinerante no contexto da educação dos Trabalhadores Rurais Sem Terra (SILVEIRA; FRIZZO; SILVA, 2010), entre outros.

Ainda, no processo de revisão bibliográfica, ficou evidente o entendimento do coletivo sobre a pesquisa. Este compreende que a pesquisa não é o único instrumento para produção do conhecimento e para a solução de todos os problemas inerentes do descaso com a educação, mas um importante elemento para essa constituição. Para tal, encontra algumas alternativas no sentido de socializar e superar problemas encontrados nas pesquisas em relação às temáticas da Formação de Professores e Prática Pedagógica. Além disso, na relação professor-estudante ou pesquisador-colaborador ambos contribuem para o aprendizado, ou como afirmou Gramsci "a relação 
entre professor e aluno é uma relação ativa, de vinculações recíprocas, e que, portanto, todo professor é sempre aluno e todo aluno, professor" (GRAMSCI, 1987, p. 37).

Embora a contribuição do F3P-EFICE seja pequena se considerada diante do desafio que é qualificar a Formação dos Professores de Educação Física e sua Prática Pedagógica, seus efeitos são significativos e tem impacto na Rede Municipal de Ensino de Porto Alegre, uma vez que possibilita uma interlocução constante entre a Universidade e esse coletivo de trabalhadores da educação. 
Contributions of the research Group F3P-EFICE to pedagogical practice and teacher training at ESEF/UFRGS and in Porto Alegre's municipal school system

Abstract: The purpose of this article was to analyze how the qualitative research group F3P-EFICE, since its constitution, has been contributing to the education of physical education students at ESEF/UFRGS and to the pedagogical practice of teachers of Porto Alegre's Municipal School System. The analytical process was accomplished under the review of the studies conducted by the group and through historical documents. It was possible to perceive from the analysis that the research group has began its work concerned with deepening studies which was able to support the pedagogical practice and training of physical education teachers.

Key-words: Research Group. Teacher Training. Physical Education

Contribuciones del grupo de investigación F3PEFICE para la formación de profesores y para la práctica pedagógica en la ESEF/UFRGS y en la red municipal de enseñanza de Porto Alegre

Resumen: En este artículo buscamos hacer un análisis cómo el Grupo de Investigación F3P-EFICE, desde su constitución, viene contribuyendo para la formación de estudiantes de formación inicial en la ESEF/UFRGS y para la práctica pedagógica de los profesores de la RMEPOA. El proceso analítico se realizó desde una revisión bibliográfica de las investigaciones hechas por el Grupo y por un análisis de documentos para conocer su breve historia. Desde las lecturas hechas, fue posible entender que el Grupo inicia sus actividades interesado en profundizar investigaciones que puedan servir de subsidio para la práctica pedagógica y para la formación de los profesores de Educación Física.

Palabras-clave: Grupo de Investigación. Formación de Profesores. Educación Física. 


\section{REFERÊNCIAS}

BERNARDI, G. B. A contribuição da formação inicial de licenciatura em Educação Física da EsEF/UFRGS para a prática docente escolar. Monografia (Conclusão de Curso) - Escola de Educação Física, Universidade Federal do Rio Grande do Sul. Porto Alegre, 2008.

BONONE, C. G. G. A prática da Educação Física na escola privada de Ensino Médio. Dissertação (Mestrado em Ciências do Movimento Humano) - Escola de Educação Física, Universidade Federal do Rio Grande do Sul. Porto Alegre, 2000.

BOSSLE, F. O "eu do nós": o professor de Educação Física e a construção do trabalho coletivo na rede municipal de ensino de Porto Alegre. Tese (Doutorado em Ciências do Movimento Humano) - Escola de Educação Física, Universidade Federal do Rio Grande do Sul. Porto Alegre, 2008.

DACOSTA, L. P. Diagnóstico de Educação Física/Desportos no Brasil. Rio de Janeiro: MEC/FENAME, 1971.

FILIPPINI, I. A organização do trabalho pedagógico na Formação Inicial de professores de Educação Física. Monografia (Conclusão de Curso) - Escola de Educação Física, Universidade Federal do Rio Grande do Sul. Porto Alegre, 2010.

FREIRE, P. A educação na cidade. 2. ed. São Paulo: Cortez, 1991.

Pedagogia da autonomia: saberes necessários à prática educativa. 6 . ed. São Paulo: Paz e Terra, 1997.

FREITAS, A. L. C. Os conteúdos escolares da Educação Física Fundamental. Dissertação (Mestrado em Ciências do Movimento Humano) - Escola de Educação Física, Universidade Federal do Rio Grande do Sul. Porto Alegre, 2001.

GRAMSCI, A. Concepção dialética da História. Rio de Janeiro, Civilização Brasileira, 1987.

GÜNTHER, M. C. C. Formação Permanente de professores de Educação Física na Rede Municipal de ensino de Porto Alegre no período de 1989 a 1999: um estudo a partir de quatro escolas da Rede. Dissertação (Mestrado em Ciências do Movimento Humano) - Escola de Educação Física, Universidade Federal do Rio Grande do Sul. Porto Alegre, 2000.

A prática dos professores de Educação Física e o currículo organizado por ciclos um estudo da Rede Municipal de Ensino de Porto Alegre. Tese (Doutorado) - Escola de Educação Física, Universidade Federal do Rio Grande do Sul. Porto Alegre, 2006. 
GÜNTHER, M. C. C.; MOLINA NETO, V. Formação permanente de professores de Educação Física na rede municipal de ensino de Porto Alegre: uma abordagem etnográfica. Revista Paulista de Educação Física, São Paulo, v.14, n. 1, p. 8597, 2000.

GÜNTHER, M. C. C; SANCHOTENE, M. U. Compartilhar as interpretações de pesquisa com os colaboradores: uma opção metodológica. In: MOLINA NETO, V; BOSSLE, F. (Org.). O ofício de ensinar e pesquisar na Educação Física escolar. Porto Alegre: Sulina, 2010.

MOLINANETO, V.; BOSSLE, F.; WITTIZORECK, E. S. Formação dos professores de Educação Física. In: TERRA, D. V.; SOUZA JUNIOR, M. Formação em Educação Física \& ciências do esporte: políticas e cotidiano. São Paulo: Aderaldo \& Rothschild : Goiânia: CBCE, 2010.

MOLINA, R. K; MOLINA NETO, V. O pensamento dos professores de Educação Física sobre a formação permanente no contexto da Escola Cidadã: um estudo preliminar. Revista Brasileira de Ciências do Esporte, Campinas, v. 22, n. 3, p. 73-85, 2001.

NEGRINE, A. Instrumentos de coleta de informações na pesquisa qualitativa. In: TRIVIÑOS, A.N.B; MOLINA NETO, V. (Org.). A pesquisa qualitativa na educação física: alternativas metodológicas. 3. ed. Porto Alegre: Editora da UFRGS/ Sulina, 2010.

NUNES, R. V.; FRAGA, A. B. "Alinhamento Astral": o estágio docente na formação do licenciado em Educação Física na EsEF/UFRGS. Pensar a Prática, Goiânia, v. 9, n. 2, p. 297-311, 2006.

OLIVEIRA, C. F. O espaço físico escolar a partir do olhar dos professores de Educação Física. Monografia (Conclusão de Curso) - Escola de Educação Física, Universidade Federal do Rio Grande do Sul. Porto Alegre, 2008.

OLIVEIRA, C. F; FILIPPINI, I; DANIEL, J. V; SILVEIRA, P. S. O olhar de estudantes de Iniciação Científica em Educação Física: o Grupo F3P-EFICE em foco. In: MOLINA NETO, V; BOSSLE, F. (Org.). O ofício de ensinar e pesquisar na Educação Física escolar. Porto Alegre: Sulina, 2010.

PERGHER, E. G. A hegemonia do esporte na escola. Monografia (Conclusão de Curso) - Escola de Educação Física, Universidade Federal do Rio Grande do Sul. Porto Alegre, 2008.

SANCHOTENE, M. U. A relação entre as experiências vividas pelos professores de Educação Física e sua prática pedagógica: um estudo de caso. Dissertação (Mestrado em Ciências do Movimento Humano) - Escola de Educação Física, Universidade Federal do Rio Grande do Sul. Porto Alegre, 2007. 
SANTINI, J. Fatores intervenientes no processo de desenvolvimento da síndrome do esgotamento profissional em professores de Educação Física. In: MOLINA NETO, V; BOSSLE, F; SILVA, L. O; SANCHOTENE, M. U. (Org.). Quem aprende? pesquisa e formação em Educação Física escolar. ljuí: Unijuí, 2009.

SILVA, G. G. Um estudo sobre a formação política na Educação Física. Dissertação (Mestrado em Ciências do Movimento Humano) - Escola de Educação Física, Universidade Federal do Rio Grande do Sul. Porto Alegre, 2009 a.

SILVA, L. O. Produção de Conhecimento (e de aprendizagem) entre sujeitos. MOLINA NETO, V; BOSSLE, F; SILVA, L. O; SANCHOTENE, M. U. (Org.). Quem aprende? pesquisa e formação em Educação Física escolar. ljuí: Unijuí, 2009 b.

SILVEIRA, P. S; FRIZZO, G. F. E; SILVA, L. O. Desafio do trabalho pedagógico do professor de Educação Física em uma escola itinerante do Movimento dos Trabalhadores Rurais Sem Terra (MST). Revista Digital Efdeportes, Buenos Aires, v. 14, n. 143, abr. 2010. Disponível em: <http://www.efdeportes.com/efd141/ escola-itinerante-do-movimento-dos-trabalhadores-rurais-sem-terra.htm>.

WITTIZORECKI, E. S. O trabalho docente dos professores de Educação Física na rede municipal de ensino de Porto Alegre. Dissertação (Mestrado em Ciências do Movimento Humano) - Escola de Educação Física, Universidade Federal do Rio Grande do Sul. Porto Alegre, 2001.

WITTIZORECKI, E. S.; MOLINA NETO, V. O trabalho docente dos professores de Educação Física na rede municipal de ensino de Porto Alegre. Movimento, Porto Alegre, v. 11, n. 1, p. 47-70, 2005. 
